\title{
Práticas, Raça e Organizações Empreendedoras: Um Estudo com Negros Empreendedores na Região Metropolitana da Cidade do Rio de Janeiro
}

\author{
Entrepreneurial Practices, Race, and Organizations: A Study with Black Entrepreneurs in \\ the Metropolitan Region in Rio de Janeiro
}

\section{Edy Lawson Silva Santos ${ }^{1}$ Josiane Silva de Oliveira ${ }^{2}$}

\begin{abstract}
Resumo
O objetivo deste artigo é discutir como as práticas de organização são influenciadas pela raça no cotidiano de trabalho dos negros empreendedores. Para isso, realizamos um estudo com negros empreendedores residentes na região metropolitana da cidade do Rio de Janeiro, Brasil. Consideramos as práticas como maneiras de fazer, a partir de Certeau (2008), e apresentamos a raça como categoria de constituição dessas práticas, pois é uma das formas, enquanto sociedade, como nos diferenciamos coletivamente no país. Como resultados da pesquisa, apresentamos o reconhecimento como negro e as feiras e as tecnologias móveis como práticas de organização dos negros empreendedores que destacam as especificidades de resistência dessa população no contexto analisado. Além disso, debates sobre como a adoção do conceito de práticas, desenvolvido por Michel de Certeau para as análises organizacionais, implica um compromisso estético, ético e polêmico no combate às opressões raciais no cotidiano organizacional. Postulamos que a dimensão ética de constituir um empreendimento pela população negra implica no rompimento estético dos silenciamentos raciais dos corpos e dos espaços sociais para que seja possível polemizar nossas diferenças como sujeitos e produtores de espaços sociais.
\end{abstract}

Palavras-chave: práticas de organização; raça; negros empreendedores.

\begin{abstract}
The purpose of this article is to discuss how organizational practices are influenced by race in the daily work of black entrepreneurs. For this, we conducted a study with black entrepreneurs living in the metropolitan region in Rio de Janeiro, Brazil. We consider practices as ways of doing, from Certeau (2008), and we present race as a category of the constitution of these practices, as it is one of the ways, as a society, how we differentiate ourselves collectively in the country. As a result of the research, we present the recognition as black and the fairs and mobile technologies as organizational practices of black entrepreneurs that highlight the specificities of resistance of this population in the analyzed context. Besides, debates about how the adoption of the concept of practices, developed by Michel de Certeau for organizational analysis, implies an aesthetic, ethical and controversial commitment in the fight against racial oppression in the organization daily. We postulate that the ethical dimension of constituting an enterprise by the black population implies an aesthetic break of the racial silences of bodies and social spaces so that it is possible to controversy our differences as subjects and producers of social spaces.
\end{abstract}

Keywords: organizational practices; race; black entrepreneurs.

Professor do Instituto Federal de Ciência e Tecnologia do Rio de Janeiro (IFRJ). Doutorando pelo Programa de Pós-Graduação em Administração da Faculdade de Economia, Administração e Contabilidade pela Universidade de São Paulo (FEA/USP). Mestre em Administração pelo Programa de Pósgraduação em Administração da Universidade Federal de Goiás (PPGADM/UFG).

Professora do Programa de Pós-graduação em Administração na Universidade Estadual de Maringá (PPA/UEM). Pesquisadora do Núcleo de Estudos Interdisciplinares Afro-brasileiros (NEIAB/UEM). Professora do Programa de Pós-graduação em Administração da Universidade Federal de Goiás (PPGADM/UFG). 


\section{INTRODUÇÃO}

O objetivo deste artigo foi discutir como as práticas de organização são influenciadas pela raça no cotidiano de trabalho dos negros empreendedores. Realizamos uma pesquisa de campo qualitativa com negros empreendedores residentes na Região Metropolitana do Rio de Janeiro, Brasil, entrevistando nove negros empreendedores, os quais relataram como a raça influencia suas práticas de organização.

A escolha do campo das práticas como base teórica para a realização deste estudo ocorreu, pois, os Estudos Baseados em Práticas (EBP) nos Estudos Organizacionais (EOR) têm se desenvolvido a partir da aproximação com diferentes áreas de conhecimento (BISPO, 2015; FELDMAN; ORLIKOWSKI, 2011). Esse processo tem possibilitado tanto o aprimoramento teórico e metodológico dos EOR como tem possibilitado o reconhecimento de diferentes fenômenos sociais como fenômenos organizacionais.

A partir desse diálogo com outros campos do conhecimento que a produção teórica de Michel de Certeau tem sido apropriada pelos EOR para a realização das análises organizacionais. Das discussões sobre estratégias (FELTON; LANGLEY, 2011), cidades (LOW, 2015) e emancipação (COURPASSON, 2017) diferentes fenômenos sociais têm sido discutidos a partir do conceito de práticas apresentado por Certeau (2008), pois, esse conceito, definido como nossas "maneiras de fazer", possibilita tanto o reconhecimento do cotidiano organizacional como base para pesquisas e discussões teóricas sobre o conceito de organização (OLIVEIRA; CAVEDON, 2013) como reconhece a necessidade de se compreender as especificidades contextuais para a compreensão da vida social.

Neste artigo, pretendemos avançar nessa apropriação teórica do conceito de práticas desenvolvido por Certeau (2008) no campo dos EOR por meio de dois caminhos. O primeiro é discutindo os elementos que caracterizam a prática para o referido autor, sendo estes os caráteres estético, ético e polêmico (CERTEAU, 1985). Debate esse ainda não aprofundado no campo dos estudos organizacionais. O segundo ponto que destacamos é considerar esse debate a partir da especificidade do contexto brasileiro. Para tanto, elencamos um dos fenômenos sociais que constitui as organizações no país: o racismo contra a população negra.

Consideramos a raça como categoria de constituição das práticas, pois é uma das formas como, enquanto sociedade, fazemos as diferenças coletivas no país, e o racismo como a forma sistemática de discriminação pautada na raça que "se manifesta por meio de práticas conscientes ou inconscientes que culminam em desvantagens ou privilégios para indivíduos, a depender do grupo racial ao qual pertencem" (ALMEIDA, 2018, p. 25). A partir desse entendimento, delimitamos os debates sobre esse fenômeno social no Brasil a partir do campo do empreendedorismo, porque, apesar dessa população compor o maior contingente demográfico no país, aproximadamente 54\% dos residentes no Brasil, uma mulher negra, por exemplo, recebe $40 \%$ do rendimento mensal médio de um homem branco (IPEA, 2017). Além disso, de acordo com dados do Sebrae (2015), do total de empregadores no Brasil, $68 \%$ são brancos, $30 \%$ são negros (incluindo pretos e pardos) e $2 \%$ são de outros grupos sociais. Apenas $9 \%$ dos empreendedores autodeclarados negros são empregadores, os outros $91 \%$ trabalham por conta própria.

A questão que se coloca é: como esse cenário de racismo contra a população negra no país é combatido por meio das práticas dessa população ao constituir um empreendimento? Para discutir esse questionamento, este artigo está estruturado em seis seções, além desta introdução. A seguir, apresentamos o referencial teórico debatendo o conceito de práticas a partir de seu caráter estético, ético e polêmico, conforme apresenta Certeau (2008). No segundo momento, realizamos uma discussão sobre o racismo contra a população negra no país destacando o campo do empreendedorismo nesse contexto. A terceira seção do artigo é dedicada à apresentação da construção metodológica do estudo. No quarto momento do artigo são descritos os resultados da pesquisa de campo e, ao final, as discussões das contribuições da pesquisa para o campo dos EBP e dos EOR, no qual consideramos que a dimensão ética de constituir um empreendimento pela população negra implica no rompimento estético dos silenciamentos raciais dos corpos e dos espaços sociais para que seja possível polemizar nossas diferenças como sujeitos e produtores de espaços sociais.

\section{REFERENCIAL TEÓRICO}

Para o desenvolvimento da proposição teórica deste estudo, esta seção está estruturada em dois momentos. Primeiramente, discutimos contribuições do conceito de práticas de Michel de Certeau a partir dos três elementos que caracterizam esse fenômeno teórico e empírico para o referido autor: o caráter estético, ético e polêmico. A seguir, realizamos um debate sobre a condição da população negra no país, destacando elementos que possibilitam compreender o empreendedorismo a partir de uma perspectiva racial.

\subsection{Práticas sociais de organização: a perspectiva de Michel de Certeau}

No campo dos EBP nos EOR, Certeau (2008) é considerado um autor de referência nesses debates devido a sua especificidade de entendimento das práticas como maneiras de fazer o cotidiano que articulam as dimensões macro e microssociais da sociedade. Para o referido autor, as práticas podem ser analisadas a partir de duas formas 
de categorizações: as estratégicas e as táticas. As práticas estratégicas se caracterizam pelo emprego de relações de forças desiguais que reconhecem e isolam sujeitos de saber e poder em determinados lugares (CERTEAU, 2008). As práticas táticas são artes dos fracos que, sem poder, jogam com o que lhes é imposto no terreno do lugar, produzindo, nesse jogo com as estratégias e lugares, espaços que temporalizam circunstâncias, buscando ganhos nos momentos oportunos, devido ao seu caráter de astúcia (CERTEAU, 2008).

Essas práticas formam o que Certeau (2008) denomina de morfologia, ou seja, produzem uma lógica de ação que formam redes de operações cujas formalidades podem ser analisadas. Nesse sentido, essa morfologia pode constituir um tipo de formalidade que denominamos de organização. As organizações podem ser consideradas como processos que se estabelecem a partir de um jogo político entre estratégias e táticas com uma configuração específica.

Esse entendimento sobre organização se aproxima do campo de estudos baseados em práticas nos estudos organizacionais. Courpasson (2017) destaca que a apropriação das discussões de Michel de Certeau para as análises organizacionais implica o entendimento de que os sujeitos sociais resistem frente à internalização das regras e normas do trabalho. Courpasson (2017) afirma que essa resistência é possível pelo fato da apropriação dos resíduos do trabalho e tempo por meio de práticas produtoras de expressões liberdade.

Certeau (1985) destaca três elementos fundamentais da natureza dessas práticas: o caráter estético, ético e polêmico. O caráter estético das práticas diz respeito ao seu estilo, às maneiras como elas utilizam os sistemas sociais impostos a todos de forma específica (CERTEAU, 1985). Por exemplo, em um processo de recrutamento de pessoas para um determinado cargo em uma organização, há elementos que são complexos de se articular para se tomar a decisão de contratação ou não. Desde a experiência profissional das pessoas, que podem ser quantificadas, aos vínculos com as políticas da organização, que são interpretados, o ato de contratar uma pessoa sintetiza um instante ligado a uma conjuntura. Sintetiza a relação da estética dessa prática com as maneiras como o que é imposto constitui especificamente naquela organização.

O caráter ético das práticas diz respeito a como os agentes das práticas se recusam ou não a se identificar com a ordem que está imposta em seu cotidiano (CERTEAU, 1985), ou seja, em que medida a prática se recusa a ser conformada às leis de fato e a produzir outros espaços, pois o espaço não é fundado em uma realidade existente, mas na vontade de criar alguma coisa. É a vontade histórica de existir.

As práticas, em seu sentido polêmico, destacam suas inserções em relações de poder, nos conflitos e contradições permanentes em nossa vida cotidiana (CERTEAU, 1985). É considerar atos de luta contra os mais fortes para o reconhecimento das diferenças e combater as desigualdades. Certeau (1985) destaca que esse caráter polêmico das práticas também evidencia que estas são coletivas, e não individuais, pois são especificidades de determinadas conjunturas.

Um dos sistemas de opressão que marcam o cotidiano de vida nas organizações brasileiras é o racismo contra a população negra. Caracterizado como "uma forma sistemática de discriminação que tem a raça como fundamento, e que se manifesta por meio de práticas conscientes ou inconscientes que culminam em desvantagens ou privilégios para indivíduos, a depender do grupo racial ao qual pertencem" (ALMEIDA, 2018, p. 25), essa sistemática também configura nossas formas de resistir e produzir gestos de insubordinação sob outras formas de constituição do cotidiano de vida e de trabalho.

No mercado de trabalho, a população negra tem sofrido historicamente com o racismo, pois, no campo econômico brasileiro, o racismo se estabeleceu a partir de uma sistemática de menor remuneração da população negra, por exemplo. Em nenhum momento da história do país a população negra apresentou paridade em relação à população branca em termos de remuneração mensal média, mesmo quando essas populações apresentam o mesmo nível de escolaridade. De acordo com dados do IPEA (2017), em que pese a população negra corresponder a aproximadamente $54 \%$ da população brasileira, o rendimento mensal médio de um homem branco no país é de $R \$ 2.509,70$; de uma mulher branca, de $\mathrm{R} \$ 1.765,00$; de um homem negro, de 1.434,10 e de uma mulher negra, de $\mathrm{R} \$ 1.027,50$.

Considerando os debates sobre o caráter das práticas, é importante refletirmos como estas têm sido utilizadas pelos negros no Brasil como forma de jogar com o sistema e colocar suas vontades históricas de existir frente a essa realidade. Pensar o triplo caráter das práticas (CERTEAU, 1985) na constituição das organizações brasileiras é se atentar para como a morfologia dessas práticas reproduzem ou reconfiguram as relações raciais no cotidiano das organizações. É destacar como, na dimensão micropolítica da vida cotidiana, a população negra "joga" com essa configuração de forma a resistir ao racismo no país.

Na próxima seção deste artigo apresentamos como esse triplo caráter das práticas cotidianas nas organizações nos auxiliam a pensar o racismo em termos organizacionais sob uma forma específica: o empreendedorismo, porque essa tem sido, desde o período em que se findou oficialmente o período de escravização dessa população no país, uma prática de sobrevivência e de resistência no campo econômico. 


\subsection{Raça e empreendedorismo no Brasil a partir das dinâmicas da população negra}

Apesar de a raça ser um fenômeno desconstruído do ponto de vista biológico, em termos sociais, ele se constitui como base de construção das relações sociais. Por isso, Hall (2003, p. 63) afirma que a raça é uma categoria discursiva, pois implica em:

[...] formas de falar, daqueles sistemas de representação e práticas sociais (discursos) que utilizam um conjunto frouxo, frequentemente pouco específico, de diferenças em termos de características físicas e corporais - cor da pele, textura do cabelo, características físicas e corporais, etc. - como marcas simbólicas, a fim de diferenciar socialmente um grupo do outro.

Na medida em que esse processo de diferenciação se estrutura a partir de conteúdos políticos, ou seja, de relações de poder, a raça se estabelece como um sistema que operacionaliza institucional e estruturalmente as organizações, produzindo o que denominamos de racismo. Por isso, afirma Almeida (2018, p. 25), o racismo se caracteriza por estabelecer "uma forma sistemática de discriminação que tem a raça como fundamento, e que se manifesta por meio de práticas conscientes ou inconscientes que culminam em desvantagens ou privilégios para indivíduos, a depender do grupo racial ao qual pertencem", então falar em racismo é falar sobre a dimensão das relações sociais produzindo especificidades em relação a como coletivamente a sociedade se organiza. Considerando as discussões de Certeau (2008) de que a constituição dessa organização perpassa nossas maneiras de fazer, e o segundo pressuposto teórico deste texto, pautado em Almeida (2018), de que a raça estrutura nossas relações sociais, consideramos que, no Brasil, nossas maneiras de fazer, nossas práticas no cotidiano, têm uma dinâmica racializada, pois esse é um fenômeno social que nos organiza enquanto coletividade.

Uma forma específica de organização em nossa sociedade é o empreendedorismo. Caracterizado como sendo um fenômeno socioeconômico de exploração de oportunidades de mercado, esse processo também é constituído pelo racismo em nossa sociedade. Os dados apresentados pelo Sebrae (2015) destacam que $91 \%$ dos negros empreendedores possuem negócio no qual trabalham sozinhos e apenas $9 \%$ são empregadores, enquanto que, entre os declarados brancos, essa diferença é reduzida substancialmente para $78 \%$ que trabalham por conta própria e $22 \%$ são empregadores. A mesma pesquisa demonstra que, do total de empregadores em 2013 em nosso país (3,6 milhões), 68\% são brancos, $30 \%$ são negros (incluindo pretos e pardos) e $2 \%$ são de outros grupos sociais.

Apesar dessas evidências, ainda são poucos os estudos que discutem raça e racismo no campo do empreendedorismo no Brasil. Em países como os Estados Unidos, por exemplo, essa discussão já está sendo realizada desde o início do século XX, em conjunto com os movimentos de direitos civis. A realidade brasileira, entretanto, ainda não desenvolveu esse debate compreendendo a dimensão econômica como dimensão de debates de direitos civis.

Um estudo que discutiu a relação entre raça e empreendedorismo foi de Davies (2009) ao discutir como a ascensão social dos negros por meio de seus empreendimentos produzem identidades híbridas desses grupos sociais, articulando elementos do segmento social de origem ao que passam a pertencer. Davies (2009) afirma que, apesar dos entrevistados se reconhecerem como negros, a raça é mobilizada como categoria para relatar e destacar a superação da discriminação racial que sofreram, reafirmando a "ideologia do sucesso". Oliveira, Pereira e Souza (2013) evidenciam como a raça influencia a criação e a manutenção de empreendimentos pela população negra. As referidas autoras, com base em estudos de Paixão (2008), destacam que a raça influencia as relações dos negros empreendedores com clientes, funcionários, concorrentes e fornecedores (OLIVEIRA; PEREIRA; SOUZA, 2013). Entre as principais dificuldades destacadas por Oliveira, Pereira e Souza (2013), estão o racismo na concessão de créditos bancários e a negociação de prazos com fornecedores, por exemplo.

De acordo com Arman (2015), as relações entre raça e empreendedorismo no Brasil, em relação à população negra, também podem ser compreendidas como estratégias de sobrevivência ou de inserção social. Justamente por essas estratégias estarem inseridas em um contexto estrutural de racismo, o empreendedorismo apresenta elementos de reprodução dessa dinâmica de discriminação racial, destacadas por Oliveira, Pereira e Souza (2013). A partir dessas proposições de Arman (2015) é possível compreender que o empreendedorismo, para a população negra, foi um fenômeno que acompanhou esse grupo social desde o início de seu processo de escravização no país. Na época da escravidão, ter o seu "próprio negócio" era a forma que muitos negros libertos do cativeiro tinham para sobreviver. Nesse sentido, o empreendedorismo não seria um fenômeno de emancipação econômica, mas uma alternativa para garantir o sustento próprio e de suas famílias por meio de serviços de culinária, costura e lavagem de roupas (ARMAN, 2015, p. 68). As baianas do acarajé de Salvador são um exemplo desse fenômeno. Ainda hoje existe uma série de assimetrias racialmente estruturadas que afetam os negros empreendedores (Souza, 2015), e o empreendedorismo surge como alternativa (às vezes, única) de renda para a alta taxa de desemprego que, no Brasil, é agravada por categorias como sexo e raça (FREIRE, 2011) e, segundo estudos como Tavares, Silva e Monarcha (2018), com negócios por necessidade.

Outros importantes estudos que evidenciaram a relevância de se discutir a raça e empreendedorismo são os de Paixão (2017; 2003). Além de destacar que os negros empreendem mais por necessidade, o referido autor 
destacou evidências sobre como o racismo opera, por exemplo, no acesso ao crédito para o estabelecimento de um empreendimento. As pessoas pretas e pardas, afirma o referido autor, têm menor acesso a crédito em instituições financeiras, sendo que as pessoas pretas têm o maior percentual de diferenciação entre os valores de créditos solicitados e obtidos para o financiamento de suas atividades (Figura 1). Paixão (2017) destaca a necessidade de órgãos públicos responsáveis pela gestão da política monetária e pela regulação do sistema creditício desenvolverem políticas de combate ao racismo diante desse quadro.

Gráfico 1 - Diferença entre valores de créditos solicitado e obtido para empreendedores

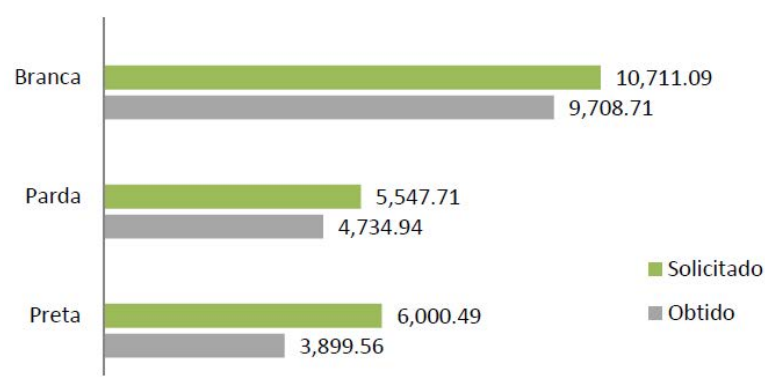

Fonte: Paixão (2017)

O empreendedorismo recebe grande influência da estratificação racial e econômica que são negligenciados por esses estudos, principalmente na área da administração (OLIVEIRA; PEREIRA; SOUZA, 2013), lacuna de pesquisas que este estudo pretende discutir. Assim, neste estudo, pretendemos realizar esse debate pensando o caráter das práticas utilizadas pela população negra para resistir nesse cenário. Na próxima seção deste artigo, apresentamos como o estudo foi desenvolvido metodologicamente durante a realização da pesquisa de campo para a produção de material empírico em relação às proposições teóricas desenvolvidas neste texto.

\section{PROCEDIMENTOS METODOLÓGICOS}

A pesquisa qualitativa (DENZIN; LINCONL, 2005) foi realizada durante o segundo semestre do ano de 2017 na Região Metropolitana da cidade do Rio de Janeiro, sendo composta pela capital, pelo município do Rio de Janeiro e os municípios circunvizinhos: "Belford Roxo, Duque de Caxias, Guapimirim, Itaboraí, Japeri, Magé, Maricá, Mesquita, Nilópolis, Niterói, Nova Iguaçu, Paracambi, Queimados, São Gonçalo, São João de Meriti, Seropédica, Tanguá, Itaguaí, Rio Bonito e Cachoeiras de Macacu" (CEPERJ, 2017). A escolha dessa localidade para a pesquisa ocorreu por ser uma das regiões metropolitanas com a maior presença de negros que empreendem no Brasil.

Em relação aos critérios de escolha dos participantes da pesquisa, foram escolhidos de acordo com dois critérios: ser negro e empreendedor. Sobre o acesso aos sujeitos, um dos pesquisadores deste trabalho visitou feiras e instituições que organizam essa população na localidade pesquisada. A partir disso, foram identificados os seguintes negros empreendedores que aceitaram participar desta pesquisa:

Quadro 1 - Participantes do estudo

\begin{tabular}{|c|c|c|c|c|}
\hline Nome & Idade & Gênero & Formação & Área de atuação do empreendimento \\
\hline Zunduri & 24 & Feminino & Técnico em Gestão ambiental & Reciclagem \\
\hline Tenkamenin & 35 & Masculino & Ensino médio & Comercio varejista \\
\hline Daomé & 38 & Feminino & Ensino superior em Letras & Acessórios \\
\hline Shamba & 42 & Masculino & Ensino médio & Produtora cultural \\
\hline Hatshepsut & 32 & Feminino & Ensino superior em Administração & Feiras e produção de eventos \\
\hline Zacimba & 28 & Feminino & Tecnólogo em Gestão de eventos & Confecção de roupas \\
\hline Nzinga & 70 & Masculino & Ensino superior em Pedagogia & Alimentação \\
\hline Ayo & 62 & Masculino & Ensino superior em Economia & Barbearia \\
\hline Saeed & 31 & Feminino & Ensino médio & \\
\hline
\end{tabular}

Fonte: da pesquisa (2017) 
É preciso destacar que todos os nomes utilizados neste artigo são fictícios e inspirados em palavras ou nomes de reis e rainhas africanos. O roteiro de entrevistas foi estruturado com base nas três grandes categorias temáticas desta pesquisa: práticas, raça e empreendedorismo. Desse modo, primeiramente, questionamos aos entrevistados sobre suas origens e formação, estabelecendo um diálogo para entender a construção de seus negócios, seu entendimento enquanto empreendedor, como eles avaliam o empreendedorismo no Brasil e, especialmente, na localidade onde residem e trabalham. Em seguida, perguntamos como eles se classificavam de acordo com os critérios raciais, quando eles se "descobriram" negros e como eles avaliam as questões raciais no Brasil, bem como o entendimento dos entrevistados sobre como as questões raciais influenciam em seu cotidiano de trabalho.

A partir desse caminho de questionamentos, identificamos as práticas desenvolvidas pelos sujeitos para a constituição de suas respectivas organizações, assim como suas relações com a questão racial da população negra no Brasil. Os resultados desses questionamentos são apresentados nas próximas seções.

\section{DESCRIÇÃO DOS RESULTADOS DA PESQUISA}

Para a apresentação dos resultados da pesquisa, destacamos três práticas descritas pelos sujeitos sociais entrevistados que articulam raça com empreendedorismo, que são: o reconhecimento coletivo como negro, as feiras de produtos de e para negros, e o uso de tecnologias móveis para a relação com o mercado.

A prática (CERTEAU, 2008) de se reconhecer como negro é uma "herança histórica" pelo fato de ser um conceito socialmente construído e cotidianamente propagado. Por isso, Munanga (2004) afirma que esse conceito está ligado a uma ideia de poder, assim como, por ser uma construção político-social, não existem marcadores estáticos para definir quem é e quem deixa de ser negro, conforma destaca Hall (2003).

[...] Eu sempre me vi como uma pessoa negra, mas a cultura negra eu não conhecia, e eu acho que essa é a grande diferença. Tanto que eu nunca fui de usar escova e sempre usei meu cabelo crespo mesmo e eu usava muita trança quando eu era pequena e, aos 15 anos, eu comecei a usar black e uso até hoje [...] Vinha a curiosidade: "de onde eu vim? Porque isso? Por que aquilo?" (Zunduri, 2017).

A prática de reconhecimento como negro tem o corpo como central em seus debates. Seja na forma das marcações simbólicas e materiais que esse corpo carrega historicamente, assim como de onde esse corpo está:

Eu sou negro, negro, eu sou negão! [...] Cara, eu nasci negro e sou negro a vida toda, mas teve... Eu vou confiar para você, eu vou te falar isso, porque é uma parada que me incomoda, porque eu faço muito evento em vários lugares, e você sabe que, nesses eventos, a quantidade de negros é minoria ou quase nula, então isso me incomoda. Se eu faço evento na Urca, amanhã mesmo eu vou estar no Lago, e você pode contar nos dedos quantos negros tem (Shamba, 2017).

O caráter estético (CERTEAU, 1985) dessa prática pode ser compreendido a partir da dimensão sistemática do racismo. A forma de utilizar a raça, ou seja, seu estético, é entendida a partir da relação com o silenciamento da presença no corpo (cabelos) e nos ambientes (minoria em eventos). Então, os sujeitos se apropriam dessa condição imposta para produzir outro estilo de ser negro. Nesse momento, o caráter ético (CERTEAU, 1985) é acionado, pois há uma recusa de identificação como a "lei dos fatos". Essa recusa polemiza a prática (CERTEAU, 1985) de reconhecimento, pois coloca em disputa o que o corpo negro pode ou não usar a partir de uma perspectiva sociohistórica, para além de um corpo a ser adornado. Por isso, o cabelo crespo, no processo de reconhecimento, produz sentido não somente pela sua adoção, mas contextualizado na história da população negra no país.

Do mesmo modo, esse é o tipo de reflexão que pauta o silenciamento da presença dos corpos negros em determinados espaços como o não reconhecimento no outro. Então, para que essa prática de reconhecimento se efetive, é necessário discutir os espaços onde os corpos e as culturas negras se fazem presentes.

As feiras são espaços de comercialização de produtos e serviços de caráter intermitente e nômade. Considerando que os espaços são lugares praticados, praticar a feira é poder produzir uma rede de apoio para a população negra, assim como ocupação da cidade. Conforme destaca Arman (2015), empreender, para a população negra, pode ser uma questão de sobrevivência não somente econômica, mas também social:

Todos os meus projetos estão voltados para o empreendedorismo afro, basicamente das mulheres, basicamente das mulheres negras, e coordenei pelo conselho do direito do negro por muito tempo e criei, junto com a coordenadora da época, uma feira chamada Africanidades, que acontece na prefeitura, no pátio da prefeitura, até hoje (Nzinga, 2017). 
Na medida em que a feira é praticada, ela produz uma rede de articulação da população negra, mas também de reconhecimento de que a cidade deve ser ocupada como forma de inserção social e econômica:

[...] No ano de 2015 que foi o grande boom das feiras étnicas aqui no Rio, porque, em 2014, só existiam As meninas black power, que é um coletivo da PUC. E aí, vendo elas e me inspirando na feira preta de São Paulo a Adriana acabou de ser reconhecida, né!? Está lá em Nova York, linda e maravilhosa, ela é meu espelho, eu falei: "Não, a gente tem que ter uma feira preta aqui no Rio, só que na periferia". Aí, em 2015, a gente fez três edições, que a ideia da feira era ser trimestral, e a gente começa a entender várias coisas (Zacimba, 2017).

A feira proporciona reflexão. É mais que um ponto de encontro e um local aonde as pessoas vão para promover o seu trabalho. Trata-se de uma construção, e o trabalho assim vai adquirindo outros contornos e significados. Assim, conforme destaca Certeau (1985), em termos do caráter estético da prática, esse produz um estilo de luta coletiva para a população negra, considerando que as próprias práticas também têm esse caráter não individual. A recusa de realização da feira no "centro econômico" da cidade, aproximando a prática da periferia, denota o sentido de polemizar as formas de ocupação da cidade, destacando a relevância de ocupação da periferia pela própria periferia.

Entretanto, considerando a dimensão macrossocial, essa prática da feira também se torna onerosa para alguns negros empreendedores. Então, um dos empreendedores entrevistados afirma que, para o pequeno empreendedor, que está iniciando seu negócio, um caminho está na utilização de alternativas tecnológicas.

Os empreendedores entrevistados trabalham com novas tecnologias, especialmente a Internet, aplicativos e redes sociais para o desenvolvimento de suas atividades. Alguns possuem site, outros realizam vendas on-line e divulgam seus negócios pelo Instagram ou Facebook. Todos eles, independentemente da idade ou da região, estão presentes com seus negócios em pelo menos uma rede social. A internet auxilia na criação de novos negócios:

[...] Aí você poderia me perguntar "E aí? eu nunca tive uma loja por que eu nunca tive uma loja?" Eu até tive vontade, ensaiei, mas quando fui ver a minha condição financeira e o que eu precisava para ter uma loja atuante, e eu sou muito exigente, eu não queria uma lojinha, eu queria um magazine... Então não, melhor não (risos). Não deu, então hoje, já há alguns anos, eu sou uma empreendedora que tem uma paleta de clientes exclusivos que só vestem comigo; eu trabalho em algumas feiras voltadas para a cultura afro, eu faço alguns eventos, os seminários que me convidam, eu vou, e enfim, hoje eu sou uma referência. Tem outras, claro, mas, das mais antigas, eu sou referência em indumentária afro-brasileira no Rio de Janeiro enquanto produtora de arte e de moda afro (Nzinga, 2017).

E, de fato, essa foi uma das dificuldades de acesso aos entrevistados. Poucos deles possuem um espaço físico, recorrendo às tecnologias digitais para solucionar esse problema:

Então uma forma de readaptar o meu negócio e não deixar ele morrer, o que é que eu vou fazer!? Eu vou trabalhar com venda on-line. Não preciso mais fazer evento, não preciso mais de deslocamento, sair de carro, carregar estrutura, ter estresse. Eu não vou precisar mais disso. Eu até posso fazer um evento ou outro, mas antes eu fazia evento todos os finais de semana (Daomé, 2017).

Courpasson (2017) afirma que as análises organizacionais com base nas discussões de práticas de Michel de Certeau devem destacar tanto como os sujeitos sociais resistem à imposição de normas quanto as formas de apropriação dos sistemas sociais para criar espações de ação frente à dominação. Então, se as formas tradicionais de ocupação de espaços tradicionais para o comércio, a exemplo de lojas em shoppings, e outros espaços são considerados para o desenvolvimento de suas atividades, a exemplo das plataformas digitais. Além disso, por meio das tecnologias digitais, é possível articular diferentes produtos e serviços em um único lugar, o que também facilita o acesso à população negra que, conforme os dados do IBGE (2017), tem os menores rendimentos mensais médios no mercado de trabalho.

A internet também é importante para o reconhecimento e pertencimento racial. Conforme destaca Zunduri, a privação de contato com práticas culturais negras, assim como de pertencimento coletivo a um grupo social racializado", é rompida com o uso de redes sociais:

1 Refere-se a relações sociais e à construção de um processo de diferenciação baseado na raça (não biológica mas social). Para aprofundar o entendimento do assunto, indicamos a leitura de A construção social da cor: diferença e desigualdade na formação da sociedade brasileira de José D’Assunção Barros, Editora Vozes, 2014. 
[...] Dentro de casa, na Internet e depois, e aí eu comecei a ir muito à Feira da Lavradio, aí na feira da Lavradio... E isso tudo sozinha sabe!? Teve um ano, há uns dois anos, eu passei andando muito pelo Rio de Janeiro sozinha, e aí descobri a feira da Lavradio e, na feira da Lavradio, encontrei um roda de Jongo. Na roda de jongo eu vi várias pessoas pretas e eu fiquei alucinada, e aí eu fui há vários sábados na feira, em várias feiras seguidas, só que eu ficava sem graça de entrar na roda, porque eu não sabia dançar, e daqui a pouco eu me vi dentro de uma dança. $E$, enfim, tem sido uma eterna descoberta. Tem sido muito gostoso ver isso tudo. Tem muita coisa por trás da cultura negra, é tudo muito rico, muito simbólico. Então tem muitos detalhes; é uma eterna busca e um eterno encontro, mas foi esse caminho até agora (Zunduri, 2017).

Então, as maneiras de fazer as tecnologias digitais podem ser consideradas a partir de seu caráter ético no sentido de que, se há uma ordem econômica de precarização dos locais de trabalho dos negros empreendedores, há uma recusa em se conformar a essa "lei de fato", com a produção de outra lógica de relação de trabalho e consumo. Isso resulta em um caráter estético coletivo de reorganização das relações de troca a partir das demandas de produtos e serviços da população negra.

\section{DISCUSSÕES}

A partir da identificação das três práticas de organização dos negros empreendedores em suas atividades, é possível compreender que o caráter estético, o ético e o polêmico dessas práticas só podem ser compreendidos a partir da dinâmica do racismo em nossa sociedade. Conforme discute Almeida (2018), o racismo é um fenômeno social que estrutura a nossa sociedade, ou seja, a nossa vida social se organiza a partir de critérios raciais. Os dados do IBGE (2002), do Ipea (2020) ou as diferentes pesquisas que foram apresentadas ao longo deste estudo (PAIXÃO, 2017) destacam as diferentes formas desse entendimento em termos econômicos, culturais ou políticos. A nossa sociedade, enquanto coletividade, tem na raça um dos principais fenômenos sociais de sua sustentação (CONCEIÇÃO, 2009). Se esse sistema é a "lei de fato", a resistência ao mesmo implica no desenvolvimento de práticas que subvertam a ordem estabelecida. Por isso, os negros empreendedores destacam inicialmente a prática do reconhecimento racial (Quadro 2) como um primeiro modo de organização de seus empreendimentos.

Reconhecer-se como negro é uma forma de se posicionar na sociedade, por isso esse reconhecimento tem a presença e o silenciamento como categorias de constituição dessa prática que se constitui nos próprios corpos desses sujeitos sociais. A presença do cabelo crespo e a ausência em espaços sociais foram elementos destacados pelos entrevistados. Sendo assim, a proposição teórica que resulta desta pesquisa é o entendimento de que a dimensão ética de constituir um empreendimento pela população negra implica no rompimento estético dos silenciamentos raciais dos corpos e dos espaços sociais para que seja possível polemizar diferenças como sujeitos e produtores de espaços sociais. Se há um silêncio de espaços para os negros empreendedores, o rompimento desses espaços ocorre com a ocupação por meio de corpos negros, que evidenciam a existência desse silenciamento. Por isso, estar presente é um ato de resistência, conforme foi apresentado pelas pessoas negras que foram entrevistadas.

Quadro 2 - Resultados da pesquisa

\begin{tabular}{|c|c|}
\hline Práticas & Descrição estética, ética e polêmica da prática \\
\hline Reconhecimento & $\begin{array}{l}\text { O corpo negro é entendido como base dessa prática para os empreendedores entrevistados, } \\
\text { pois é a sua presença política que possibilita reconfigurar as dinâmicas dos espaços sociais. }\end{array}$ \\
\hline Feiras & $\begin{array}{l}\text { Praticar as feiras é produzir espaços para desconstrução da ausência negra em nossa } \\
\text { sociedade, reconfigurando os modos de ocupação das cidades. }\end{array}$ \\
\hline Tecnologias digitais & $\begin{array}{l}\text { O uso das tecnologias móveis é uma prática de reconfiguração das relações de e com o } \\
\text { trabalho para os negros empreendedores }\end{array}$ \\
\hline
\end{tabular}

Fonte: da pesquisa.

Como forma de potencializar essa prática do reconhecimento, outra prática destacada pelos negros empreendedores foi a realização de feiras. Considerando a dimensão estrutural do racismo (ALMEIDA, 2018), esse processo só pode ser desestabilizado também coletivamente, por isso o reconhecimento como negro não está relacionado somente a uma perspectiva individual, mas ao reconhecimento no coletivo. Reconhecer-se como negro implica reconhecer-se com o outro, então a organização social da população negra se torna uma dimensão base para enfrentamento do racismo.

Neste estudo, a organização coletiva da população negra tem como uma de suas categorias principais de análise a econômica, considerando o empreendedorismo como uma prática desse contexto. As feiras foram apresentadas como uma forma de produção de espaço social (CERTEAU, 2002) de rompimento do silenciamento da população negra em espaços econômicos. Além disso, ao romper com esse silenciamento econômico, que é ético, as trocas 
que acontecem nesses espaços se constituem como forma de reafirmação das práticas de reconhecimento racial, destacando a estética da prática, assim como de fortalecimento de parcerias entre a população negra, polemizando essas relações. Essa evidência empírica é importante para a desconstrução do mito da não existência de solidariedade entre a população negra no país (PINTO; FERREIRA, 2014).

De acordo com Pinto e Ferreira (2014), o ideal de branqueamento, uma das bases que marcam o racismo no Brasil, tenderia a interferir no sentimento de solidariedade e de pertencimento coletivo dos negros, de forma a torná-los mais frágeis. Entretanto, conforme foi observado ao longo deste estudo, há uma tendência de que o reconhecimento racial em espaços coletivos tende a fortalecer a solidariedade racial, tendo a dimensão socioeconômica como uma das dimensões de mediação para isso.

A terceira prática identificada neste estudo, o uso de tecnologias móveis, foi descrita como maneira pela qual essa mesma população tem acesso a elementos que reforçam e ressignificam a prática do reconhecimento por meio da reconfiguração das relações de e com o trabalho. O uso das tecnológicas móveis possibilitam romper com a estética das trocas econômicas, pois os espaços para que essas trocas se efetivem não precisam mais ser físicos, mas virtuais. Então, os silenciamentos produzidos pelo racismo, ao ser constituído por meio da dimensão econômico, são reconfigurados, possibilitando ir além de ampliar mercados, pois há maior exposição dos produtos e serviços produzidos pelos negros empreendedores, para além de suas localidades, reforçando o caráter ético da prática ao fortalecer os vínculos entre essa população e romper com essa dimensão de não solidariedade do racismo entre os negros.

Desse modo, a Internet, por exemplo, é importante não só para a construção e manutenção dos negócios, mas para a construção pessoal e reconhecimento enquanto negro, pois assim como nos espaços físicos, nos espaços virtuais essas referências também são identificadas e compartilhadas.

Ao considerarmos as discussões sobre práticas de Certeau (1985) articuladas ao racismo estrutural (ALMEIDA, 2018) no contexto do empreendedorismo, é possível compreender que a estética negra empreendedora tem relação com as maneiras de rompimento de mecanismo de funcionamento do racismo na vida cotidiana. Por isso, para os empreendedores, o seu próprio corpo é um espaço que deve ser pensado como parte do processo de construção de seus empreendimentos. A textura do cabelo ou as cores das roupas são ações de reconhecimento racial e de fortalecimento de suas atividades socioeconômicas, até porque o consumo de produtos para esse reconhecimento também advém das relações estabelecidas com outros negros que são empreendedores.

Essa dimensão estética tem relação com o caráter ético das práticas, pois há uma recusa à ordem estabelecida de branqueamento e de não solidariedade entre a população negra, resultado do racismo contra a população negra no Brasil. Nesse sentido, a ética das feiras é romper com o silenciamento de espaços econômicos para a população negra, de forma a polemizar esses espaços a partir da ótica racial. Essa polemização implica numa dimensão de denúncia de silenciamentos, reconhecimento de desigualdades e estabelecimento de ações de reparação dessas desigualdades. E as ações coletivas se constituem como as principais maneiras de efetivação dessa polemização.

Sendo assim, para além de um processo econômico, para a população negra, estabelecer empreendimentos implica um processo social ético de rompimento de mecanismos que sustentam o racismo estrutural no Brasil. Em que pese que somente empreender não seja a via que efetive a desconstrução dessa estrutura de opressão racial, o empreendimento se torna um espaço de reconhecimento individual e coletivo de pertencimento não pautada pelo outro, mas a partir da construção de elementos e práticas culturais da própria população negra.

Por isso, a dimensão ética do empreender implica a construção de estéticas de ser e de se relacionar com outras pessoas negras para que o sentido de coletivo seja reconfigurado para além das relações de poder que segregam racialmente os espaços sociais em nossa sociedade. As feiras são os espaços que possibilitam que a ética e a estética se interpelem materialmente nas relações sociais, que são polêmicas, nas palavras de Certeau (1985). Essa contribuição teórica desta pesquisa também destaca a necessidade de se repensar a centralidade econômica e o não reconhecimento de relações de poder e estruturas sociais que constituem o fenômeno do empreendedorismo a partir de singularidades de constituição da sociedade. O que ficou evidente neste estudo, e que apresentamos de forma sintetizada em nosso argumento teórico, é que são as articulações de diferentes categorias sociais na construção do racismo no Brasil a base de constituição dos empreendimentos. Se a segregação racial provoca clivagens que limitam e delimitam onde e como as pessoas negras podem e devem empreender, é preciso considerar como os privilégios produzidos pelo racismo estrutural, conforme discute Almeida (2018), também operam nessa dinâmica.

\section{CONSIDERAÇÕES FINAIS}

Com o objetivo de discutir como as práticas de organização são influenciadas pela raça no cotidiano de trabalho dos negros empreendedores, realizamos uma pesquisa na Região Metropolitana da cidade do Rio de Janeiro, Rio de Janeiro. A partir do material empírico produzido com as entrevistas realizadas com nove pessoas negras que empreenderam em diferentes setores econômicos, e com as discussões sobre o caráter ético, estético e polêmico das práticas, de acordo com Certeau (1985), no contexto do racismo estrutural brasileiro (ALMEIDA, 2018), é possível realizar suas considerações. 
A primeira é que considerar as discussões sobre os caráteres de constituição das práticas apresentados por Certeau (1985) tem dois pontos importantes para as análises organizacionais em termos raciais. O primeiro é o reconhecimento da raça como constituidora das organizações (OLIVEIRA, 2018; ROSA, 2014; CONCEIÇÃO, 2009). Sendo o racismo um sistema de práticas que estrutura e institucionaliza a sociedade brasileira a partir da produção de privilégios e desvantagens (ALMEIDA, 2018), e a raça como fenômeno social que diferencia grupos sociais, racializar as análises organizacionais é discutir como aproximadamente $54 \%$ da população brasileira resiste frente a um processo reproduzido pelas organizações brasileiras, inclusive para a defesa de suas próprias vidas (BORGES, 2018).

O segundo ponto a se destacar é que assumir a perspectiva das discussões sobre práticas de Michel de Certeau é assumir um compromisso ético de análise organizacional que destaque conjunturas de rompimento da ordem estabelecida nas organizações para a produção de outros espaços. Quando consideramos a raça como categoria de análise desse processo, estamos nos atentando para como, no cotidiano, os sujeitos sociais se articulam para combater o racismo por meio de um compromisso estético, ou seja, um estilo de gestão que se inscreva e intervenha no sistema racial brasileiro o polemizando de forma a defender a vida da população negra em todos os processos organizacionais.

Sendo assim, do ponto de vista teórico, buscamos contribuir com as análises organizacionais, especificamente com o campo dos EBP, a partir de uma perspectiva racial, que busca adotar a postura teórica de Certeau (2008) para compreender as organizações, assumindo um compromisso estético, ético e polêmico contra os sistemas de opressão que constituem as organizações. Além disso, também destacamos que, enquanto um sistema de práticas institucionalizadas em nosso país, o racismo é um dos sistemas pelos quais os processos organizativos se constituem e se sustentam em nossa sociedade. Desse modo, foi possível contribuir com o campo dos estudos organizacionais com o entendimento de que a dimensão ética de constituir um empreendimento pela população negra implica no rompimento estético dos silenciamentos raciais dos corpos e dos espaços sociais para que seja possível polemizar nossas diferenças como sujeitos e produtores de espaços sociais.

Esse entendimento foi construído considerando que os espaços e as trocas econômicas no país são estabelecidos a partir do processo de segregação racial que estrutura as nossas relações sociais. Além do efeito de a população negra apresentar rendimento mensal médio e ocupar postos de trabalhos não operacionais abaixo da composição demográfica dos negros no Brasil, o racismo estrutural também silencia a presença negra na constituição de empreendimentos econômicos em nosso país.

Por isso, constituir um empreendimento, para as pessoas negras, assim como para a sociedade brasileira, implica discutir eticamente como os sistemas sociais impõem modos de vida para determinados grupos sociais (CERTEAU, 1985) a partir do critério racial. Apesar de a raça ser uma categoria social que tem sido apresentada como importante reflexão na constituição dos espaços organizacionais (OLIVEIRA, 2018), no campo do empreendedorismo, entendendo este como um espaço organizacional (SANTOS, 2017), é um debate que ainda precisa ser aprofundado; especialmente para se compreender como a raça pode ser um fator de privilégio em uma sociedade como a nossa, debate que ainda não foi realizado na área de Administração, o que indicamos como uma das possibilidades de agenda futura de estudos a partir dos resultados desta pesquisa.

Do ponto de vista estético, empreender, para a população negra, também implica em um processo de reconhecimento racial para além do que historicamente tem sido imposto para essa população no Brasil. Essa dinâmica resultou na percepção dos negros empreendedores de seus corpos e dos espaços onde eles são silenciados. Então, a estética de rompimento do silenciamento resultou no reconhecimento dos traços negros em seus corpos, a exemplo dos cabelos e da cor da pele. Por isso, as feiras são espaços em que os negros empreendedores podem romper com esses silenciamentos, além de produzir sentidos de solidariedade e de compartilhamentos entre as pessoas negras.

$\mathrm{O}$ uso das tecnologias digitais, especialmente a Internet, se estabeleceu como uma das práticas que medeiam esses processos raciais e socioeconômicos que interpelam e constituem os empreendimentos das pessoas negras. Além de mediar a questão econômica, pois os empreendedores entrevistados não têm recursos financeiras suficientes para ter um espaço físico para o desenvolvimento de suas atividades, sendo a venda on-line uma das formas de resistência frente a essas imposições socioeconômicas, as pessoas negras entrevistadas têm a vida como empreendedores impactada pela construção de raça e do "lugar" do negro no Brasil.

Conforme discute Kilomba (2016), o racismo tem a ver com responsabilidade e posicionamento. Responsabilidade no sentido de reconhecer e reparar como, na vida cotidiana, assumimos posicionamentos que podem ser revistos, reconsiderados e reformulados em um processo histórico de rompimento com as clivagens e segregações que marcam a nossa sociedade. É isso que Certeau (1985) nos chama a atenção quando destaca a necessidade de se considerar o caráter ético, estético e polêmico que produzem nossas organizações. Essa responsabilidade e posicionamento são considerados pelos negros empreendedores na medida em que destacam a relevância coletiva de sua atuação socioeconômica, mas também de reconfiguração das relações raciais em nossa sociedade.

Sendo assim, esperamos que as discussões que propomos com essa pesquisa possam ser consideradas em outros contextos sociais, de forma que possamos compreender de forma mais profunda como a raça também é uma categoria social que se constitui como base nos processos organizativos. Para que os debates sobre como o racismo estrutural opera em nossa sociedade, também é necessário discutir questões de gênero, classe social, sexualidade em intersecção com a raça, de forma a evidenciar as singularidades dos processos sociais. Será que ser negra e 
mulher produz especificidades quando se empreende? Ou existem contextos em que a sexualidade se torna mais marcante na definição sobre o que e onde empreender a partir do critério racial? São questionamentos que poderão ser colocados em discussão em outros estudos.

Porém, além dessas questões, é preciso, conforme apresentamos neste texto, considerar a produção de privilégios nos processos organizativos. Se há evidências de que ocupar um local de opressão racial em nossa sociedade impacta diretamente nas dinâmicas das organizações, será que quem ocupa outros espaços, a exemplo de privilegiados, tem noção desse posicionamento, buscando estabelecer práticas que, em seu caráter ético, estético e polêmico, de alguma forma, rompam com esse processo de segregação racial que marca as estruturas sociais em nosso país? Retomando Kilomba (2016), reconhecimento e posicionamento são aspectos importantes quando falamos sobre racismo. E você, leitor? Como é o seu processo de reconhecimento e de posicionamento frente ao racismo contra a população negra em nosso país?

\section{REFERÊNCIAS}

ALMEIDA, S. O que é racismo estrutural. Belo Horizonte: Letramento, 2018.

ARMAN, A. P. Empreendedorismo entre mulheres negras na cidade de São Paulo. RAU - Revista de Administração do UNISAL, Campinas, v. 5, n. 8, p. 64-82, 2015.

BISPO, M. de S. Methodological reflections on practice-based research in organization studies. Brazilian Administration Review, [S. I.], v. 12, p. 309-323, 2015.

CENTRO ESTADUAL DE ESTATÍSTICAS, PESQUISAS E FORMAÇÃO DE SERVIDORES PÚBLICOS DO RIO DE JANEIRO. Mapa da região metropolitana do Rio de Janeiro. Link. Acesso em: 25 out. 2017.

CERTEAU, M. A invenção do cotidiano: artes de fazer. Petrópolis: Vozes, 2002. 352 p.

CERTEAU, M. Teoria e método no estudo das práticas cotidianas. In: SZMRECSANYI, M. I. Q. F. (org). Cotidiano, cultura popular e planejamento urbano. São Paulo: FAU: USP, 1985. p. 3-17.

CONCEIÇÃO, E. B. A negação da raça nos estudos organizacionais. In: ENCONTRO NACIONAL DOS PROGRAMAS DE PÓS-GRADUAÇÃO EM ADMINISTRAÇÃO, 33., 2009, São Paulo. Anais [...]. Rio de Janeiro: ANPAD, 2009. p. 1-16.

COURPASSON, D. The politics of everyday. Organization Studies, [S. I.], v. 38, n. 6, p. 843-859, 2017.

DAVIES, F. A. Identidades de sucesso: breve reflexão sobre os empresários negros brasileiros. Plural, São Paulo, v. 16, n. 2 , p. $75-94,2009$.

DENZIN, N. K.; LINCOLN, Y. S. The handbook of qualitative research, London: Sage, 2005.

FELDMAN, M. S.; ORLIKOWSKI, W. J. Theorizing practice and practicing theory. Organization Science, [S. I.], v. 22, n. 5 , p. 1240-1253, 2011.

FELTON, C.; LANGLEY, A. Strategy as practice and the narrative turn. Organization Studies, [S. I.], v. 32, n. 9, p. 1171-1196, 2011.

FREIRE, D. A. L. O jovem e o empreendedorismo no Brasil: oportunidade ou necessidade? Revista Gestão e Desenvolvimento, Novo Hamburgo, v. 8, n. 1, jan. p.83-91, 2011.

HALL, S. Da Diáspora: identidades e mediações culturais. Belo Horizonte: UFMG, 2003.

IBGE. Censo demográfico 2010. Brasília: IBGE, 2017.

IPEA. Retrato das desigualdades de raça e gênero. Brasília: IPEA, 2017.

KILOMBA, G. A máscara. Cadernos de Literatura em Tradução, [S. I.], n. 16, p. 171-180, 2016.

LOW, K. E. Y. The sensuous city: sensory methodologies in urban ethnographic research. Ethnography, [S. I.], v. 16, n. 3, p. 295-312, 2015. 
MUNANGA, K. A difícil tarefa de definir quem é negro no Brasil. Estudos Avançados, São Paulo, v. 18, n. 50, p. 51-66, 2004.

OLIVEIRA, J. S. As influências raciais na construção do campo etnográfico: um estudo multissituado no contexto Brasil-Canadá. Organizações \& Sociedade, Salvador, v. 25, n. 86, p. 511-531, 2018.

OLIVEIRA, J. S; CAVEDON, N. R. Micropolíticas das práticas cotidianas: etnografando uma organização circense. Revista de Administração de Empresas, [S. I.], v. 53, n. 2, p. 156-168, 2013.

OLIVEIRA, J. S; PEREIRA, J. A.; SOUZA, M. C. D. Empreendedorismo, cultura e diversidade: a participação dos empreendedores negros nas atividades empreendedoras no Brasil no período de 1990 a 2008. Contextus, Fortaleza, v. 11, n. 2, p. 7-30, 2013.

PAIXÃO, M. J. P. Acesso ao crédito produtivo pelos microempreendedores afrodescendentes: desafios para a inclusão financeira no Brasil. Salvador: BID, 2017.

PAIXÃO, M. J. P. Destino manifesto: estudo sobre o perfil familiar, social e econômico dos empreendedores/as afro-brasileiros/as dos anos 1990: relatório final de pesquisa. Rio de Janeiro: Pnud, 2003.

PINTO, M. C. C.; FERREIRA, R. F. Relações raciais no Brasil e a construção da identidade da pessoa negra. Pesquisas e Práticas Psicossociais, São João del-Rei, v. 9, n. 2, p. 257-266, dez. 2014.

ROSA, A. R. Relações raciais e estudos organizacionais no Brasil. Revista de Administração Contemporânea, Rio de Janeiro, v. 18, n. 3, p. 240-260, 2014.

SANTOS, E. L. S. Relações raciais e empreendedorismo: um estudo sobre negros empreendedores na região metropolitana do Rio de Janeiro. 2017. 168 f. Dissertação (Mestrado em Administração) - Universidade Federal de Goiás, Goiânia, 2017.

SEBRAE. Os donos de negócio no Brasil: análise por raça/cor (2003-2013). Brasília: SEBRAE, 2015.

SOUZA, H. R. C. O papel do BNDES e do SEBRAE no fomento e na capacitação do empreendedorismo negro brasileiro. In: CONGRESSO DE PESQUISADORAS(ES) NEGRAS(OS) DO SUDESTE, 1., Nova Iguaçu, Anais [...]. Rio de Janeiro: ABPN, 2015. p. 1-11.

'TAVARES, A. C. S; SILVA, P. M.; MONARCHA, H. M. C. Afroempreendedorismo e o movimento black money: um estudo de caso: espaço art ato. Revista de Comunicação e Cultura na Amazônia, Belém, v. 4, p. 102-128, 2018.

\section{Contato:}

Edy Lawson Silva Santos

E-mail: edy.santos@ifrj.edu.br

Josiane Silva de Oliveira

E-mail: josiane.ufg@gmail.com

Submetido em: 24/07/2019

Revisado em: $23 / 04 / 2020$

Aprovado em: 18/08/2020 